\title{
LICENCIATURAS
}

\section{IMPORTÂNCIA DA RESIDÊNCIA PEDAGOGICA PARA FORMAÇÃO DE PROFESSORES: SABERES NECESSÁRIOS PARA A PRÁTICA DOCENTE.}

\section{IMPORTANCIA DE LA RESIDENCIA PEDAGÓGICA PARA LA FORMACIÓN DE PROFESORES: CONOCIMIENTO REQUERIDO PARA LA PRÁCTICA DOCENTE.

\author{
IMPORTANCE OF PEDAGOGICAL RESIDENCE FOR TEACHER TRAINING: \\ KNOWLEDGE REQUIRED FOR TEACHING PRACTICE.
}

\author{
Apresentação: Comunicação Oral \\ Palloma Joyce de Aguiar Silva ${ }^{1}$; Wilson Antônio da Silva²; Flávio José de Abreu Mouraㄹ; \\ Aline Furtuozo de Sousa ${ }^{4}$; Ronaldo Dioniso da Silva ${ }^{5}$.
}

\section{DOI: https://doi.org/10.31692/2358-9728.VICOINTERPDVL.2019.0166}

\begin{abstract}
Resumo
O presente trabalho tem como objetivo refletir sobre a importância da atuação no campo escolar na construção da identidade docente de estudantes de licenciatura em química que estão no processo de formação inicial, a partir de uma experiência no âmbito do Programa de Residência Pedagógica, em uma escola de Referência em Ensino Médio da rede estadual de Pernambuco, situada no município de Vitória de Santo Antão, com estudantes de $1^{\mathrm{a}}$ e $2^{\mathrm{a}}$ séries do ensino médio. As atividades têm se tornado uma peça chave para o processo formativo, considerando a articulação com a teoria e prática. Podemos considerar que uma das grandes dificuldades no ensino de ciências é a formação dos próprios professores. Nesse sentido, as experiências vivenciadas na graduação refletem na prática do professor, positiva ou negativamente, quando, posteriormente, se encontrar atuante na sala de aula. Um dos desafios profissionais do professor cada vez mais é estimular e motivar os estudantes, pois, é comum no ensino básico o relato de crescente desinteresse pela disciplina de química, devido, , inclusive, ao fato de o ensino tender a uma concepção mais tradicional. Desta forma, os estudantes não enxergam a disciplina como uma ciência fundamental para as nossas vidas. É neste contexto de desafios que o presente trabalho se circunscreve, destacando a importância da teoria associada à prática para o processo de formação do docente que atuará junto aos alunos do ensino básico. As atividades realizadas têm o papel de promover a reflexão sobre a prática, buscando novas formas de ver e fazer, na construção da identidade de docente.
\end{abstract}

\footnotetext{
${ }^{1}$ Licenciatura em Química, Instituto Federal de Pernambuco, palloma_joyce_aguiar@hotmail.com

${ }^{2}$ Licenciatura em Química, Instituto Federal de Pernambuco, Wilson.antonio98@hotmail.com

${ }^{3}$ Licenciatura em Química, Instituto Federal de Pernambuco, flavio.jose33@hotmail.com

${ }^{4}$ Licenciatura em Química, Instituto Federal de Pernambuco, alinefurtuozo@yahoo.com

${ }^{5}$ Doutor, Instituto Federal de Pernambuco, Ronaldo.dionisio@gmail.com
} 
Palavras-Chave: Formação de professores, Ensino de ciências, Ensino-aprendizagem.

\begin{abstract}
Resumen
Este artículo tiene como objetivo reflexionar sobre la importancia de actuar en el campo escolar en la construcción de la identidad docente de los estudiantes de pregrado de química que están en el proceso de educación inicial, a partir de una experiencia dentro del Programa de Residencia Pedagógica en una escuela Oficial de referencia de la escuela secundaria de la Escuela Estatal de Pernambuco, ubicada en la ciudad de Vitória de Santo Antão, con estudiantes de $1^{\circ}$ y $2^{\circ}$ grado de la escuela secundaria. Las actividades se han convertido en una parte clave del proceso formativo, considerando la articulación con la teoría y la práctica. Podemos considerar que una de las grandes dificultades en la enseñanza de las ciencias es la formación de los propios docentes. En este sentido, las experiencias vividas en el pregrado se reflejan en la práctica del profesor, positiva o negativamente, cuando, más tarde, se activa en el aula. Uno de los desafíos profesionales del maestro es estimular y motivar cada vez más a los estudiantes, porque es común en la escuela primaria el informe de un creciente desinterés en la disciplina de la química, debido al hecho de que la enseñanza tiende a una concepción más tradicional. De esta manera, los estudiantes no ven la disciplina como una ciencia fundamental para nuestras vidas. Es en este contexto de desafíos que el presente trabajo es limitado, destacando la importancia de la teoría asociada con la práctica para el proceso de formación docente que trabajará con los estudiantes de educación básica. Las actividades realizadas tienen el rol de promover la reflexión sobre la práctica, buscando nuevas formas de ver y hacer, en la construcción de la identidad docente.
\end{abstract}

Palabras Clave: Formación del profesorado, enseñanza de las ciencias, enseñanzaaprendizaje.

\begin{abstract}
This paper aims to reflect on the importance of acting in the school field in the construction of the teaching identity of undergraduate chemistry students who are in the process of initial education, from an experience within the Pedagogical Residency Program in a school High School Reference Officer of the Pernambuco State School, located in the city of Vitória de Santo Antão, with students from the 1st and 2nd grades of high school. Activities have become a key part of the formative process, considering the articulation with theory and practice. We can consider that one of the great difficulties in science teaching is the formation of the teachers themselves. In this sense, the experiences lived in the undergraduate reflect in the teacher's practice, positively or negatively, when, later, is active in the classroom. One of the teacher's professional challenges is increasingly to stimulate and motivate students, because it is common in elementary school the report of growing disinterest in the discipline of chemistry, due to the fact that teaching tends to a more traditional conception. In this way, students do not see discipline as a fundamental science for our lives. It is in this context of challenges that the present work is limited, highlighting the importance of theory associated with practice for the process of teacher education that will work with students of basic education. The activities performed have the role of promoting reflection on the practice, seeking new ways of seeing and doing, in the construction of teacher identity.
\end{abstract}

Keywords: Teacher Education, Science Teaching, Teaching-Learning 


\section{Introdução}

É possível notar que nos dias atuais, embora tenhamos muitos avanços na sociedade e na tecnologia, ainda persistem alguns problemas didático-pedagógicos relacionados ao ensino das ciências, especificamente nas áreas como: física, matemática e química (descontextualização, fragmentação excessiva de conteúdos, falta de articulação e distanciamento entre teoria e prática, visão tradicional do trabalho docente e do ensino, entre outros). Em geral, esses problemas não ocorrem apenas nas salas de aulas do ensino básico, mas também nos próprios cursos de formações de professores. Sendo assim, acabamos formando professores que, na maioria das vezes, possuem medo de inovar ou dificuldades para fazê-lo no intuito de proporcionar novas formas de perceber o saber para os seus estudantes. Assim, muitas vezes, os conteúdos estudados nas salas de aula acabam por não apresentar sentido ou relação com o cotidiano. Entretanto, podemos perceber que esses problemas, na maior parte dos casos, vêm desde a formação inicial dos docentes, nos cursos de formação de professores, que tratam conceitos científicos desatrelados das metodologias de ensino em aulas que, acabam por ser, por diversas vezes, completamente tradicionais, considerando os papéis onde o professor transmite o conteúdo e o licenciando reproduz nas provas. Nesse sentido, Lima (2008) destaca que a área das Ciências da Natureza (especificamente, Química e Física), tem apresentando diversas lacunas, estando relacionada à abordagem tradicional do processo, bem como ao seu próprio campo de atuação: na maioria das vezes, os estudantes vão para o campo de atuação e discutem o processo educacional apenas nas disciplinas de estágio, mas, no dia a dia da graduação, os aspectos educacionais não são sequer tangenciados.

Por diversas vezes, o que os estudantes de licenciatura e do ensino básico mais relatam, acerca das aulas de química, é que precisam se preocupar em memorizar os conteúdos, nomes e fórmulas, sem necessariamente ver sentido algum de aprender a disciplina na sua compreensão de mundo, pois, de nada servirá para as suas vidas cotidianas. Esse é um problema com o qual deparamos com grande frequência: a falta da apropriação do saber, pois, como sabemos, muitos conteúdos de química são bastante abstratos e muitos professores não conseguem associar com o cotidiano dos estudantes. Desta forma, acaba-se por recorrer à memorização, pois determinado conteúdo será "cobrado" nas provas. Outro aspecto que podemos destacar é baixa frequência de atividades mais participativas e lúdicas como: jogos e 
experimentação, mesmo sendo atividades que possuem uma grande contribuição para o processo de ensino-aprendizagem.

Outro aspecto que gera bastante discussão é articulação entre a teoria e a prática (práxis), que devem caminhar de mãos dadas com os processos educacionais para a formação de professores, pois, ambas se complementam na construção de uma compreensão mais sólida da realidade, dos processos e desafios da prática docente. Muitas das vezes, no processo de formação inicial ou mesmo na formação continuada, é dada uma grande ênfase na teoria, nos conceitos e conhecimentos de caráter conteudista. Entretanto, a atuação prática fica à parte, muitas vezes discutida apenas nas disciplinas ditas pedagógicas e delegadas a uma compreensão minimalista de sua importância, gerando um grande problema na hora de exercer a profissão no ambiente de trabalho.

Muitos aspectos do processo de ensino tradicionalmente concebido decorrem dessa dificuldade de, mesmo na graduação, compreender, discutir e atrelar conhecimentos pedagógicos e conhecimentos conceituais. Uma realidade possível é a formação de professores que não conseguem perceber a importância de olhar para o processo de formação dos seus estudantes, e acabam por focar suas energias apenas em notas e na compreensão memorística das ciências.

É nesse sentido que o Programa Residência Pedagógica foi idealizado. Tem o objetivo de proporcionar aos docentes em formação inicial, o contato direto com o espaço escolar em geral, com estudantes, professores e todas as atividades escolares, se tornando uma peça chave para a formação de futuros professores, tornando possível o diálogo entre a teoria a prática docente. O programa de Residência Pedagógica tem como suas premissas principais o entendimento de que a formação de docentes nos demais cursos da licenciatura tem o maior foco na formação de qualidade, por meio de projetos que fortaleçam o campo da prática docente e excitando de uma maneira ativa na questão da teoria e da prática profissional, pois na maioria das vezes, o próprio estágio curricular não consegue suprir essas necessidades, para que se torne possível à promoção de um ensino de qualidade em escolas de educação básica. Utilizando coleta de dados e diagnósticos sobre o ensino e a aprendizagem escolar, entre outras didáticas e metodologias e também induzir sobre a reformulação da formação prática nos cursos de licenciatura, tendo por base a experiência da residência pedagógica e também fortalecer, ampliar e consolidar a relação entre a IES e a escola, promovendo sinergia 
entre a entidade que forma e a que recebe o egresso da licenciatura e estimulando o protagonismo das redes de ensino na formação de professores.

\section{Fundamentação Teórica}

Sabemos que é por meio das interações sociais, a vida acadêmica, o estudante e futuro professor possuem várias experiências que irão possibilitam o seu amadurecimento profissional, Zeichner (1993), tem uma grande valorização nas atitudes reflexivas do professor, destacando a grande importância de se considerarem as condições sociais em que este está inserido, ou seja, o seu campo da atuação. Nóvoa (1992) também propõe essa formação numa perspectiva denominada de crítico-reflexiva, apontando três processos na formação do professor: desenvolvimento pessoal, desenvolvimento profissional e desenvolvimento organizacional

Pois como sabemos, na maioria das vezes, a teoria é completamente diferente da prática. Muitos autores expressam suas preocupações acerca das metodologias que são utilizadas nos cursos de formação Gatti, (2010); Nóvoa, (1992); Holanda e Silva, (2013), pois eles defendem a ideia que os currículos estão repletos de disciplinas que não acabam favorecendo conhecimentos teóricos-práticos, sendo assim os professores não se sentem preparados para a realidade.

No qual Pimenta e Lima (2004) destacam acerca da disciplina de estágio supervisionado, estando apenas resumindo em observar os professores na sala de aula e imitar os seus modelos, nos dificultando na hora de lidar com as situações no ao vivo e a cores. Como sabemos, nada mais importante do que a própria prática docente para a formação, no qual Schön (1992) destaca três pontos de grande importância, como, reflexão na ação, reflexão sobre a ação e reflexão sobre a reflexão na ação.

Dando continuidade a esse pensamento, Nóvoa (1992) e Freire (1996) frisam que formação não se dar apenas de bagagens de cursos, técnicas e de conhecimentos, mas é claro que por meio de vivências, desta forma sendo possível refletir de uma forma crítica acerca das práticas.

Pimenta (2006), também destaca que referente a formação de professores, é completamente diferente da sua realidade, de como realmente acontece no chão da escola e que os conteúdos estudados são completamente diferentes da realidade, sendo assim necessário a união da 
teoria com a prática, no qual podemos enxergar ao vivo e a cores a realidade do cotidiano de um docente em sala de aula.

Desta forma, sendo importante a valorização de competências para o processo de formação de professores. Incentivar a formação de docentes em nível superior para a educação básica; elevar a qualidade da formação inicial de professores nos cursos de licenciatura; inserir os licenciandos no cotidiano de escolas da rede pública de educação, proporcionando-lhes oportunidades de criação e participação em experiências metodológicas, tecnológicas e práticas; (GUIMARÃES, 2013, p.2-3).

\section{Metodologia}

Este trabalho tem caráter qualitativo e apresenta um estudo de caso, no intuito de compreender e investigar as ações que são desenvolvidas no âmbito do Programa Residência Pedagógica por uma estudante do curso de Licenciatura em Química do Instituto Federal de Ciência e Tecnologia de Pernambuco. O estudo teve como base para os resultados, as experiências acerca de toda trajetória da discente no programa, que teve início no segundo semestre de 2018 e deverá ter sua conclusão no segundo semestre de 2019.

A experiência foi desenvolvida em uma Escola de Referência em Ensino Médio do Estado de Pernambuco, localizada no município de Vitória de Santo Antão, com estudantes de $1^{\mathrm{a}}$ e $2^{\mathrm{a}}$ series do Ensino Médio sob a supervisão da professora da disciplina de química da instituição. O percurso metodológico foi pautado com registro das aulas e análises das seguintes etapas, considerando a importância de todos esses passos na reflexão e na construção identitária da Licencianda:

- Produções de plano de atividades;

- Realização de atividades e regência em sala de aula;

- Observações de aulas;

- Cursos de formação.

Sendo assim, buscamos analisar de qual forma o programa de residência vem contribuindo para as ações que estão sendo desenvolvidas nas escolas, se os resultados estão sendo construtivos, se o mesmo vem também contribuindo para formação da discente do curso de química, e o que ele vem acarretando para a sua formação acadêmica, como identidade como professora, e também para os estudantes das séries do ensino médio. 


\section{Resultados e Discussão}

Com base nas atividades realizadas, entre elas, observações de aulas, planejamentos e realização de atividades com os estudantes de ensino médio, foi possivel observar a grande contribuição do programa para formação de futuros docentes de química. As atividades desempenhadas tornaram a residente mais próxima do contexto escolar, considerando uma vivência profissional, de vinculo à instituição e busca por desenvolver trabalhos, discutir e compartilhar das propostas educacionais desenvolvidas na escola campo. A presença constante, a atuação com os estudantes e interação com os profissionais da insttituição no dia a dia contribuem para reconhecer possibilidades, desafios próprios do contexto educacional e do papel docente.

Os contextos de vivências estão organizados por categoria de atividades, de forma a facilitar o registro e a discussão desses dados, entretanto, isso não significa que as atividades foram temporalmente próximas, a regência, as observações de aula e as atividades extracurriculares perpassaram todo o processo e se sobreporam, tornando o processo ainda mais rico e orgânico.

\section{- Plano de aula}

Uma das maiores dificuldades nnos momentos de regência, éacerca na realização dos plsnos de ualas, na organização de todo planejamento da aula, no qual com os acompanhamentos dos professore sorientadores, nos quais todas as orientações são dadas para a oranização e produção do mesmo, assim consegundo superar uma grande dificuldade na hora dos planejamentos das atividades.

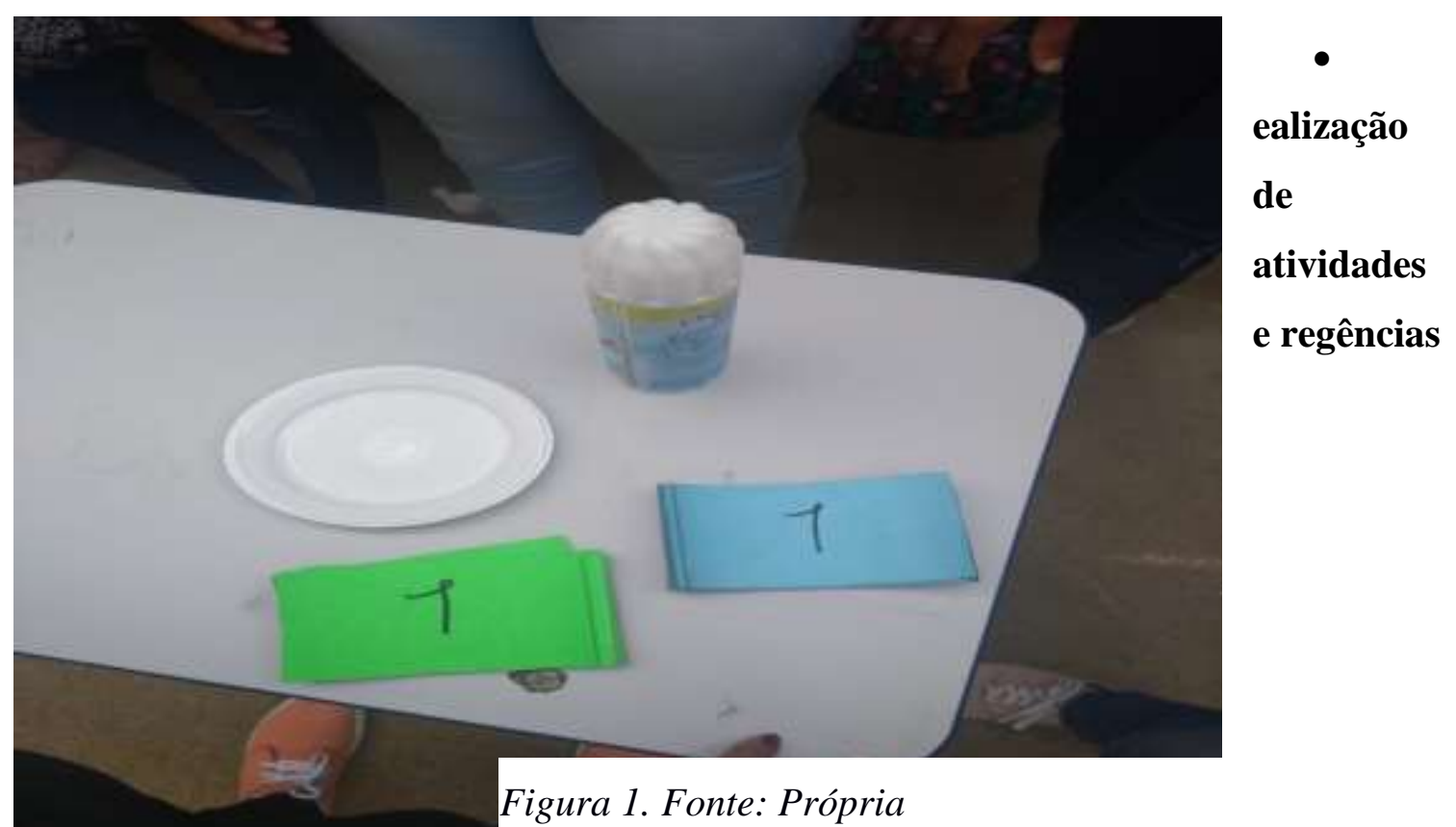




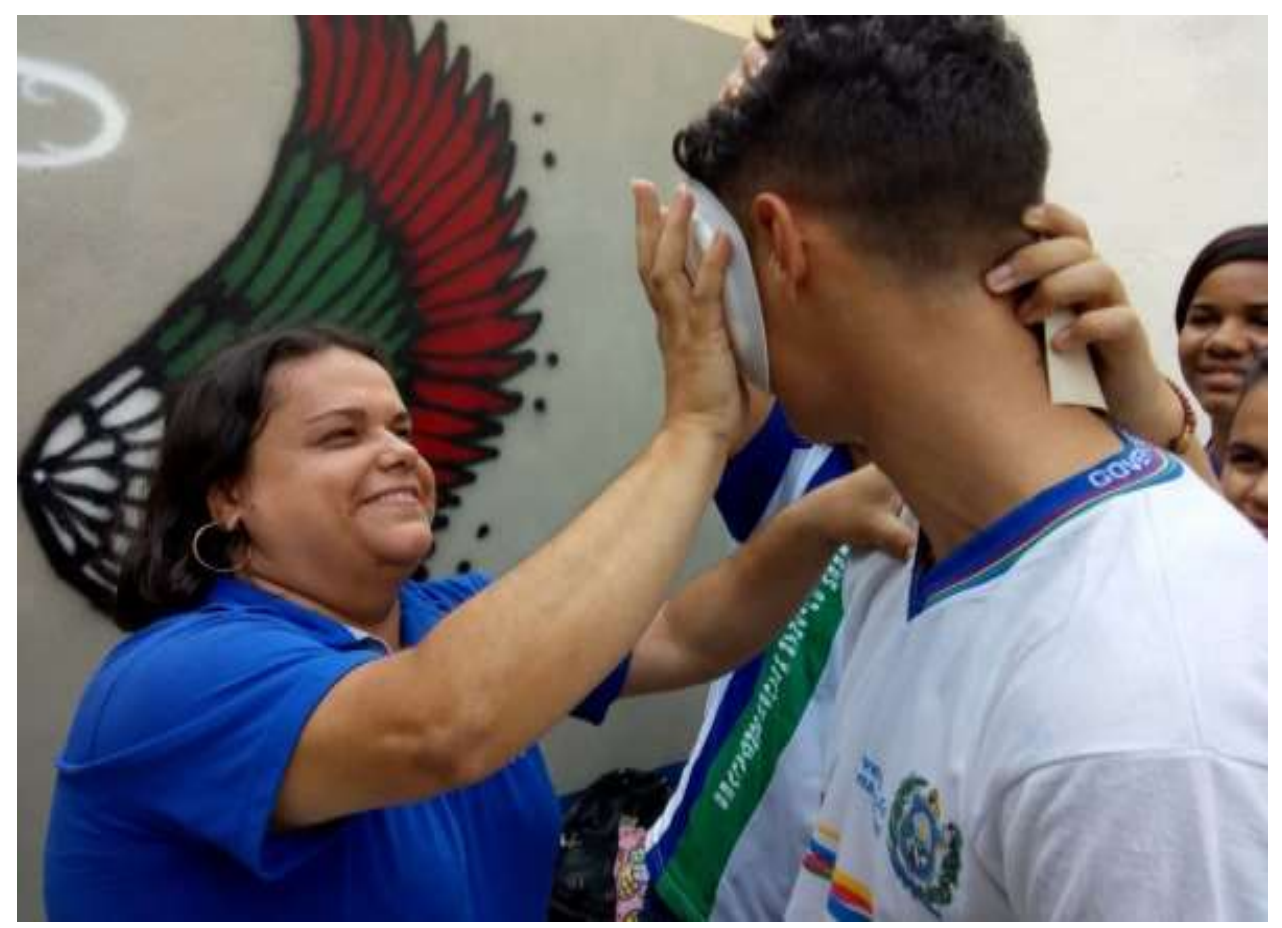

Figura 2. Fonte: Própria

Referente à imagem 1 e 2, relacino qual foi proporcionado aos estudantes uma introdução ao conteúdo, com resoluções de questões, abordando os conceitos teórico e calculos matématicos, em por final, ocorreu uma realização de uma dinamica com os mesmo,

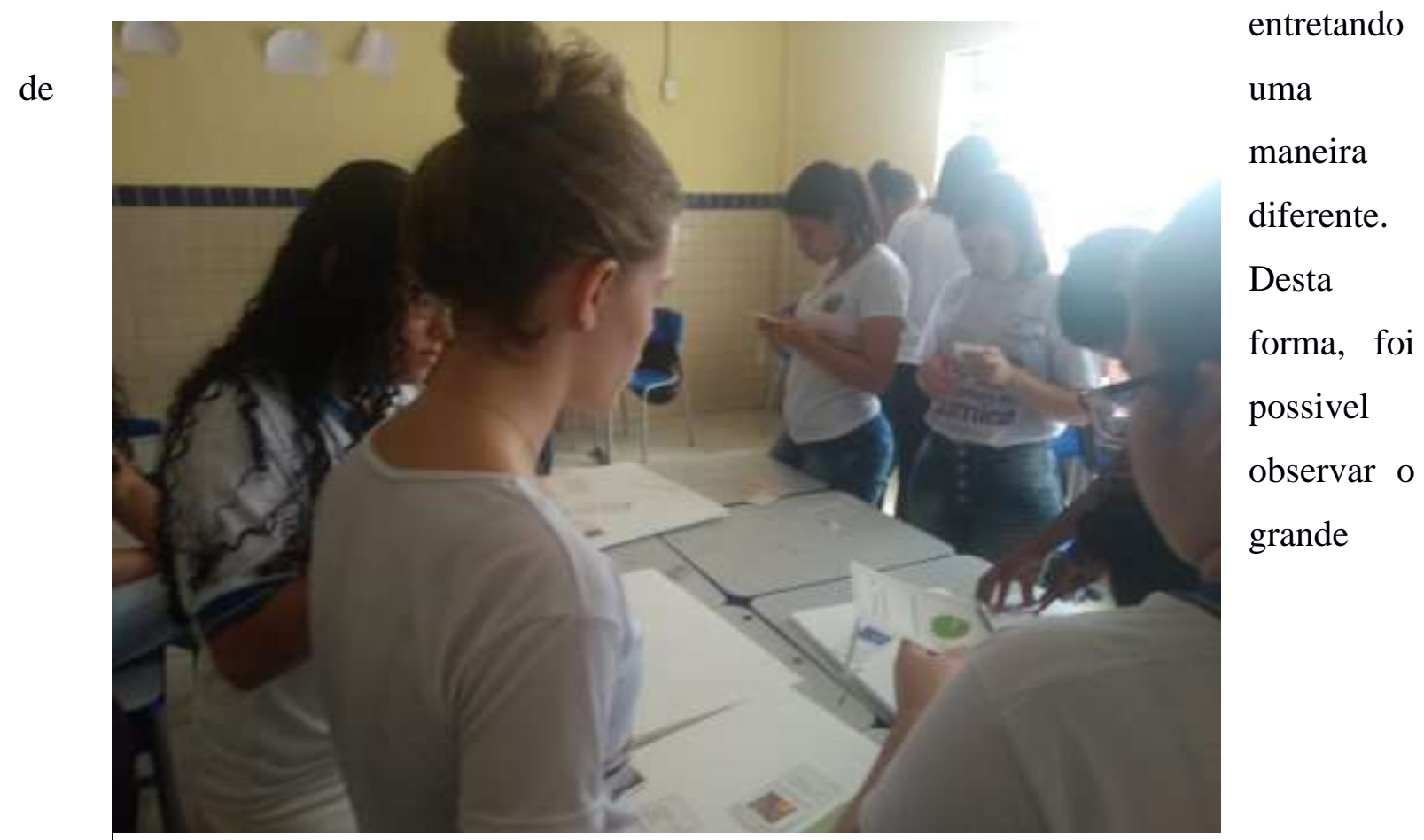

Figura 3. Fonte: Própria 
desempenho dos estudantes nas resoluções das quesões, pois, ate mesmo estudantes que não tinham o habito de participar das aulas, se tornaram mais ativos diante do processo didático realizado, assim, sendo possivel notar um resultado satisfatoria diante da forma que o contéudo foir abordado.

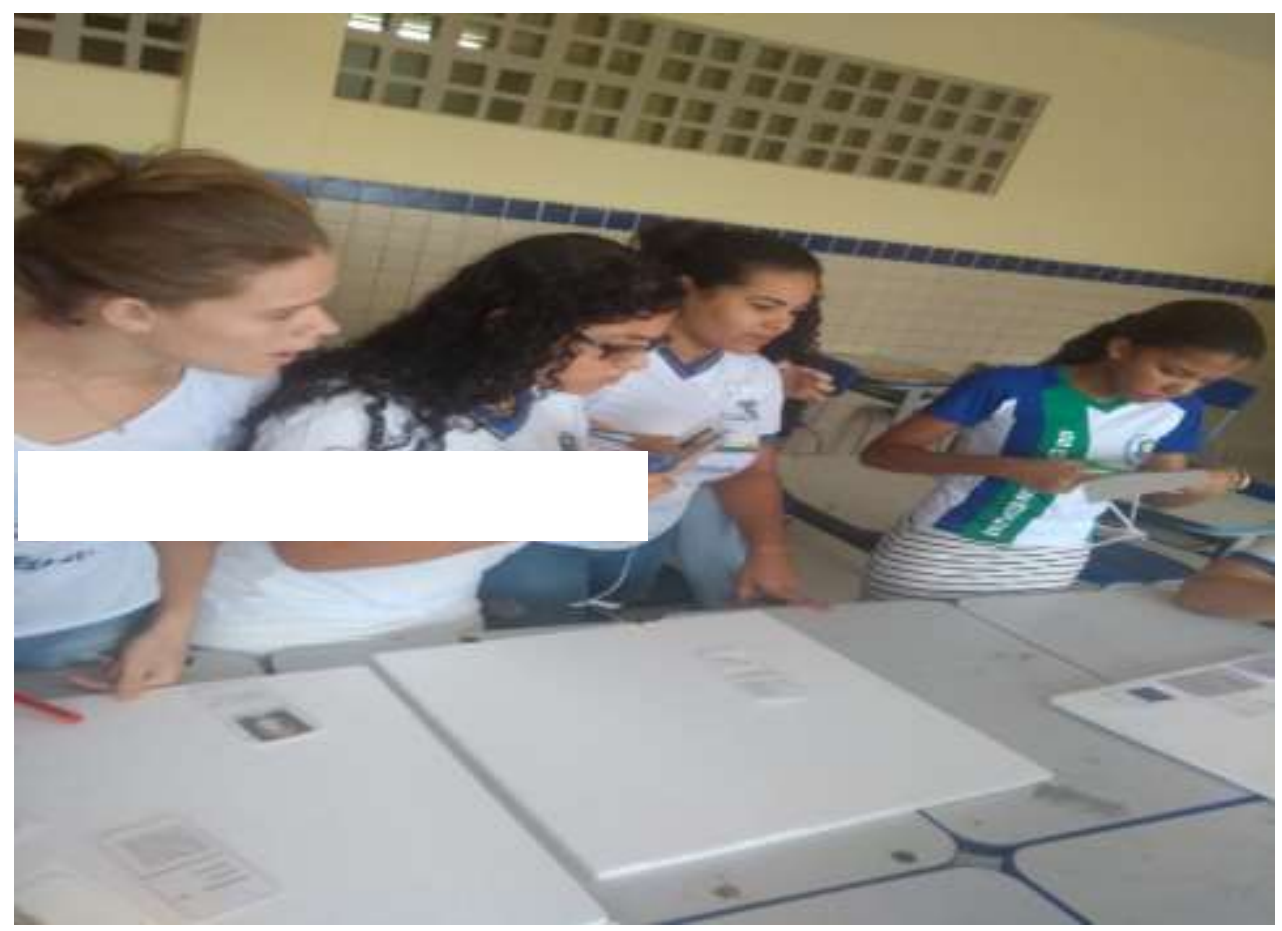

Figura 4. Fonte: Própria

Com base na imagem 3 e 4, na qual foi realizado uma atividade com a aplicação do jogo Domino de Transformações químicas e físicas, sendo os prpoprios estudantes partcipando do processo de montagem, e logo em seguida aplicado para revisão do conteúdo já abordado pela professora, no qual a mesma relatou que os estudantes tiverem um grande desempenho no desenvolvimento da atividade. Nisto, podemos destacar agrande contribuição da utilização de 
jogos didáticos para melhor apropriação dos conhecminetos químicos, sabendo o quando sua utilização é de grande valia para o processo de ensino e aprendizagem.

- Observações do espaço e das atividades extracurriculares

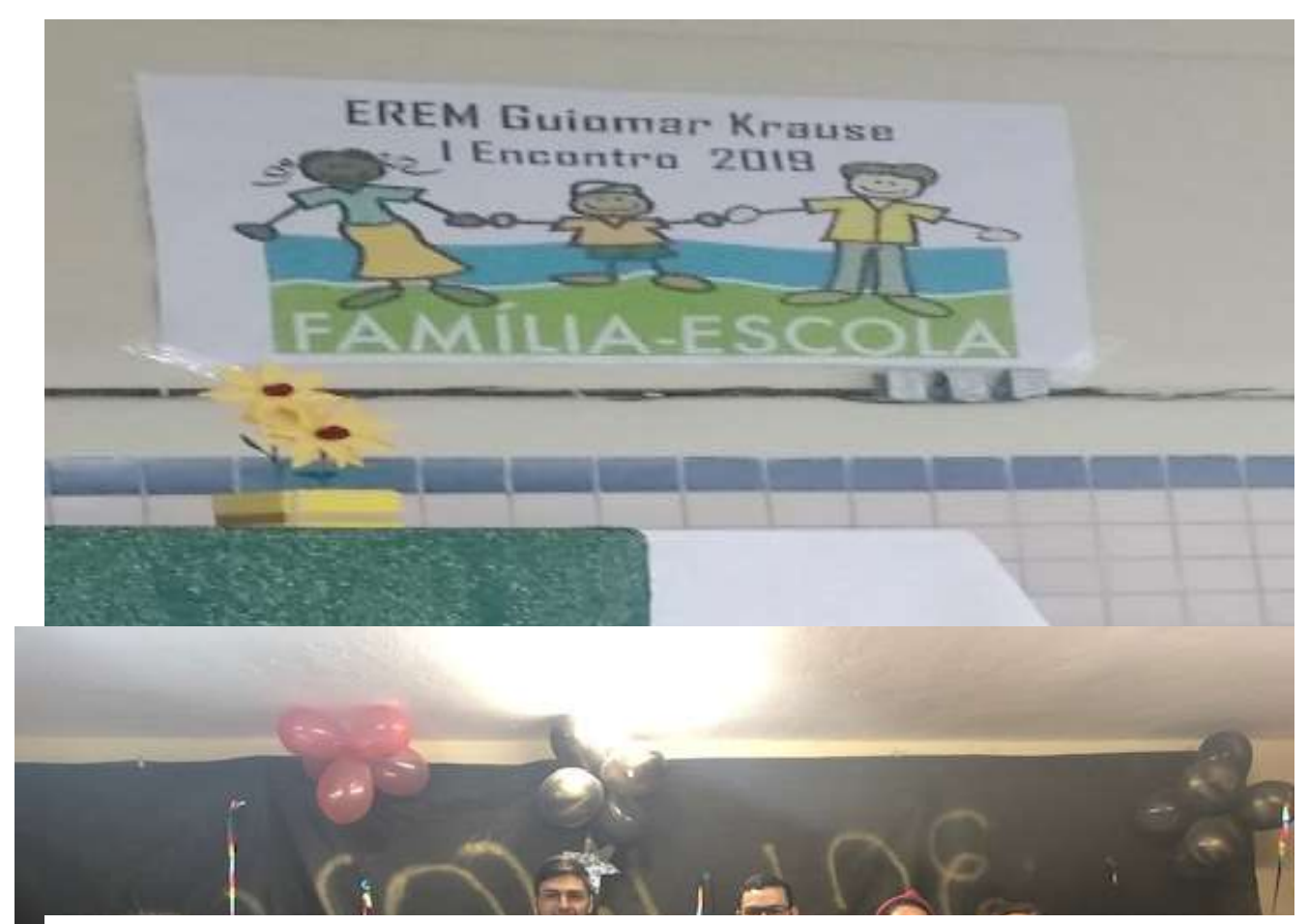

Figura 5. Fonte: Própria

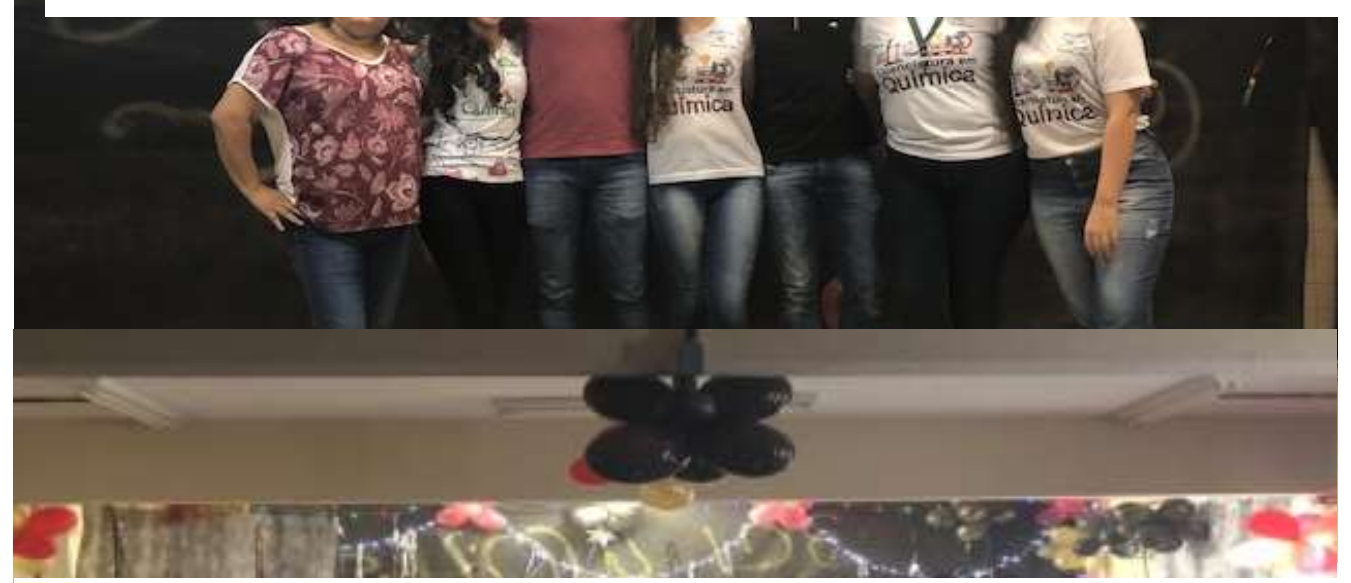

Figura 6. Fonte: Própria

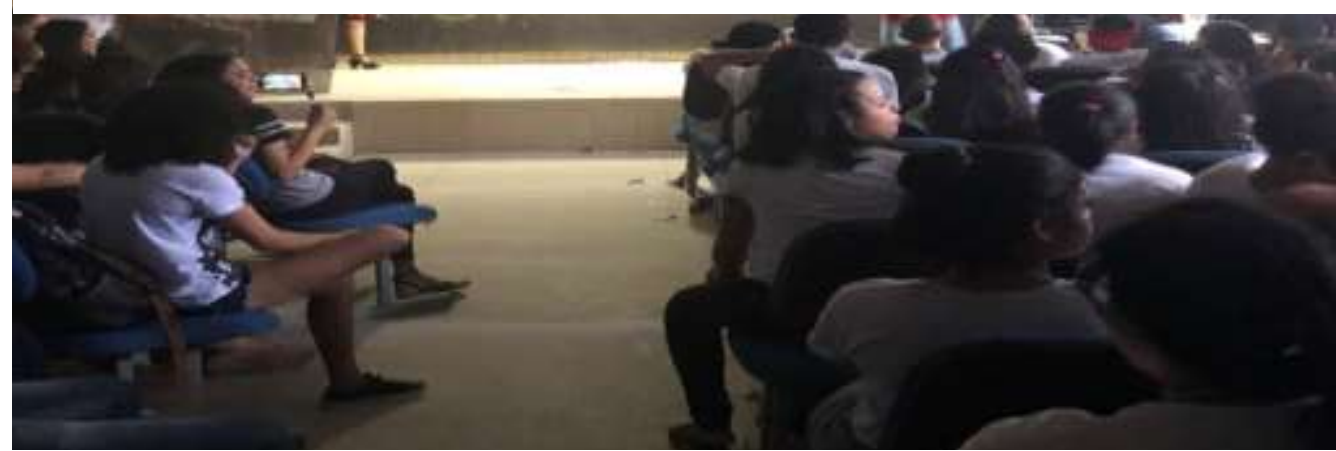

Figura 7. Fonte: Própria 
Outro aspecto bastante importante durante esse periodo da residência, foi acerca das atividades extra-curriculares realizadas na escola, no qual da maioria das vezes, a familia faz parte deste processo, pois sabemos como é de grande valia para o processo de ensino e aprendizagem a participação da familia ativa no ambiente escolar. Outro ponto muito importante, nas realizações dos eventos escolares, é a questão da procupação do estudante como um ser, pois buscam o tempo todo potencializar talentos dos mesmos, os fazendo se sentir como uma parte ativa do proceeso.

- Observações de aula

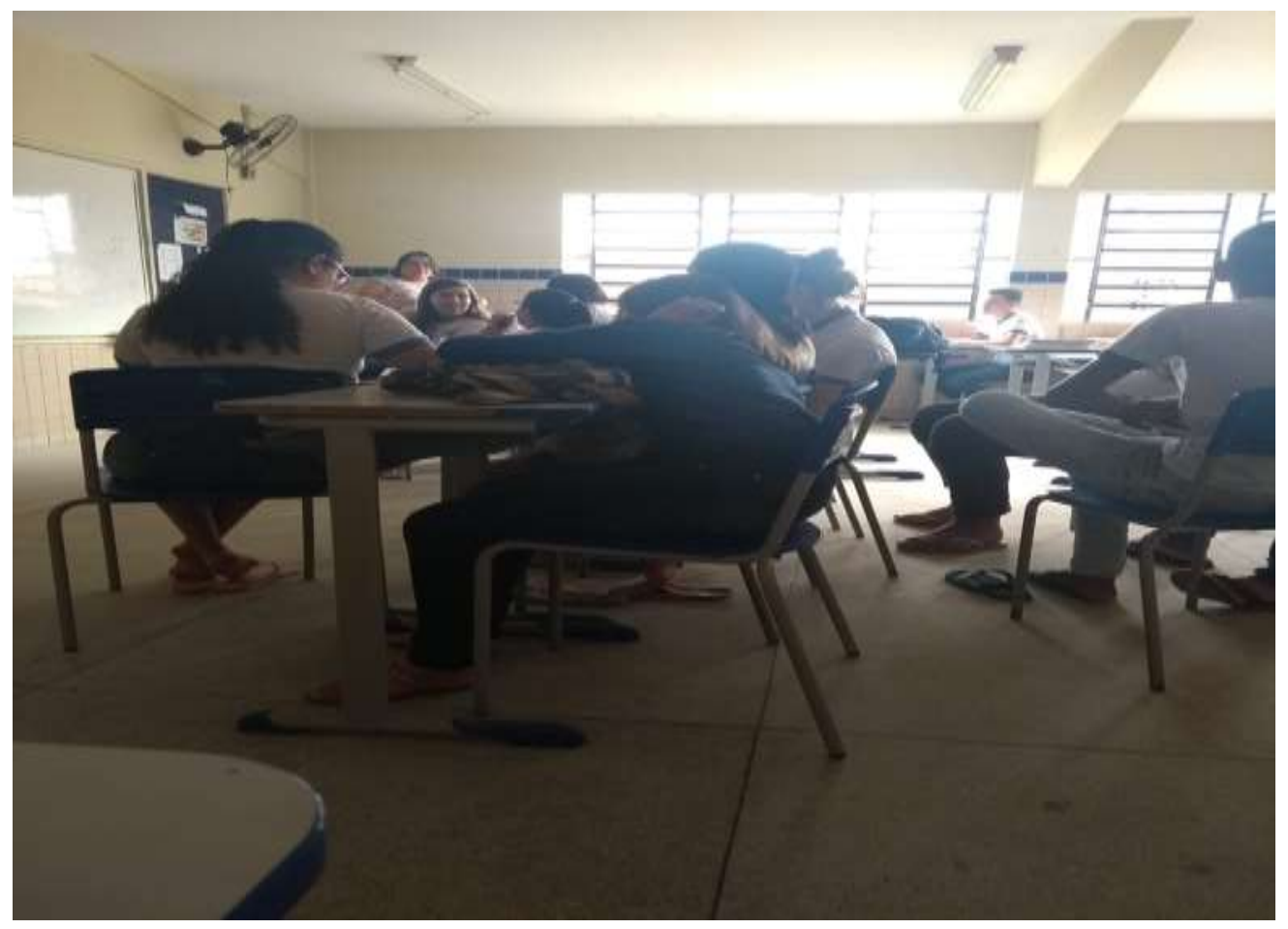




\section{Figura 8. Fonte: Própria}

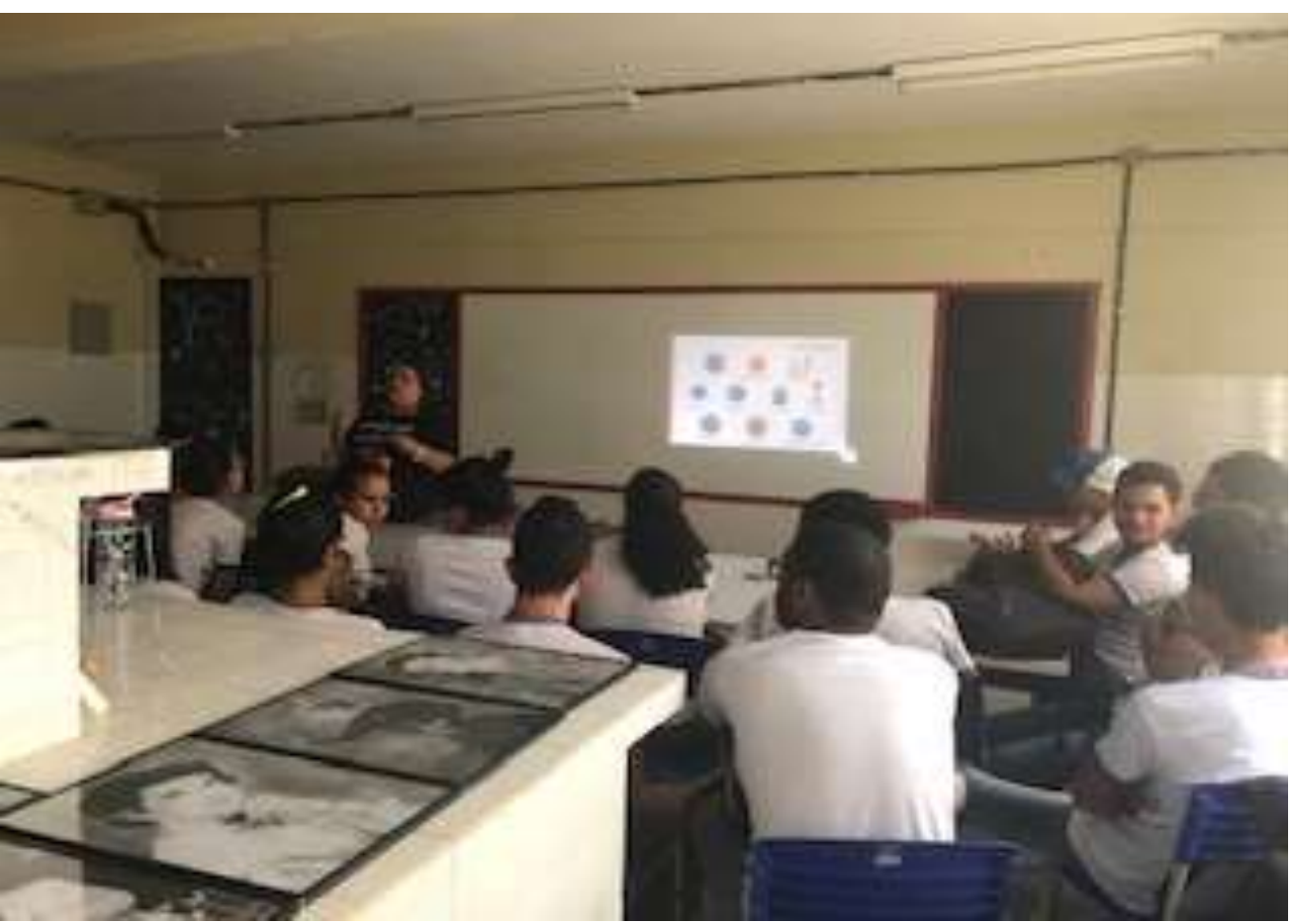

Figura 9. Fonte: Própria

Importante destacar antes de qualquer coisa, a importância das observações de aulas, pois é nele o momento analisar e conhecer a turma, poendo assim se apropria de pontos importantes que contribuem ou não para o desenvolvimento das atividades. No qual tivemos esse tempo para melhor conhecimento do funcionamento da turma, escola, relação da professora com os estudantes, e nada menos importante do que o dominio de sala, pois como sabemos, na grande maioria das vezes é um dos principais problemas para um professor. Foi possivel notar o quanrto a relação professor aluno intefere no processo de ensino e aprendizagem, pois a partir do momento que o professor consegue alcançar a confiança do aluno, e virse versa, se torna mais gostoso e interessante de se aprender.

\section{- Cursos de formações}

Vivenciamos experiências de grande valia para nossa formação, pois nos foram proporcionados cursos de formações para apropriação de didáticas diferenciadas, como por exemplo, formação de jogos de didáticos, para expansão dos nossos conhecimentos e assim podendo proporcionar aos estudantes e aos residentes, satisfação no processo de ensino e aprendizagem. 


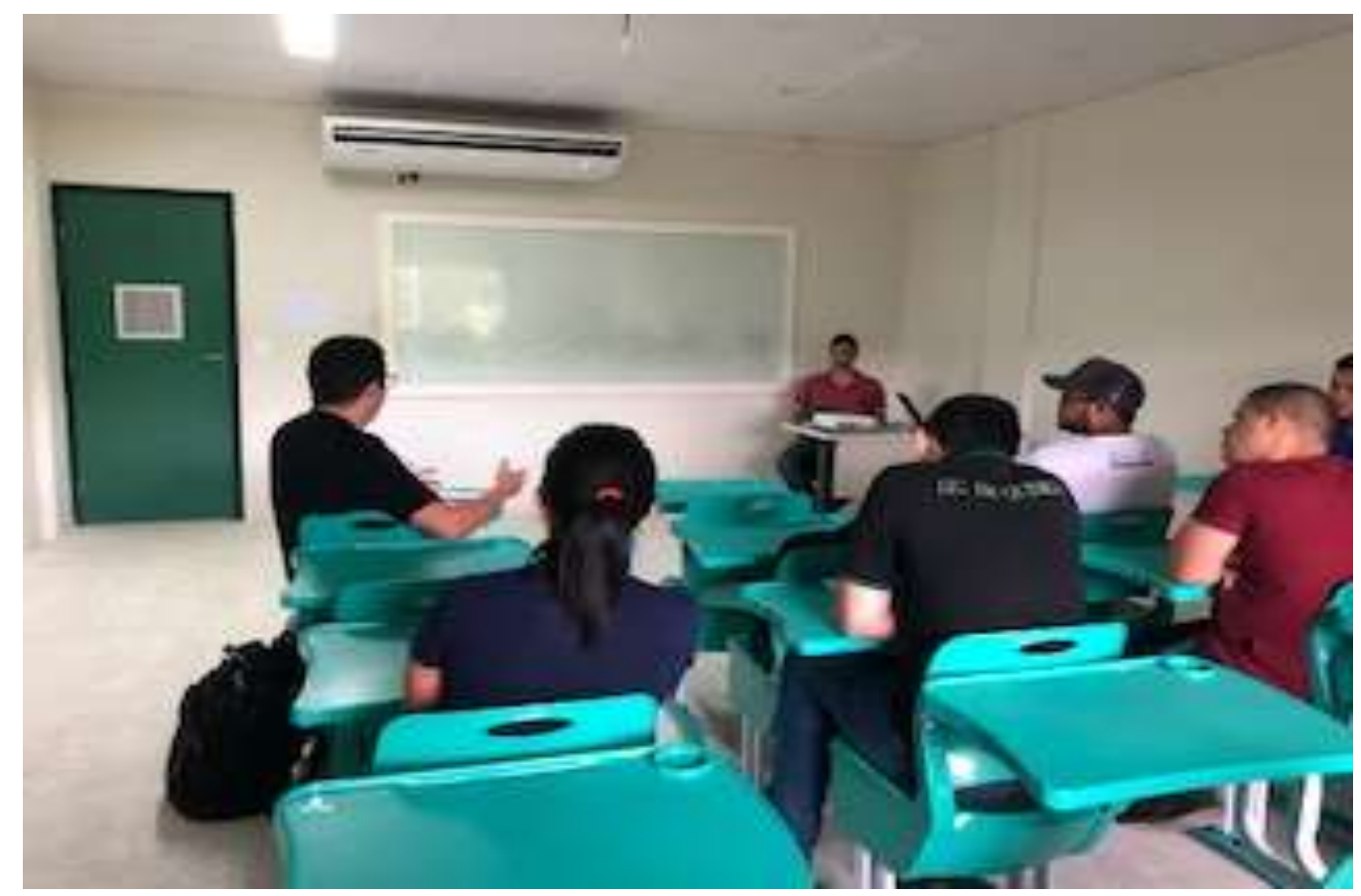

Figura 10. Fonte: Própria

\section{Conclusões}

Com base na vivência na escola Guiomar Krauses, foi possível notar a grande colaboração do Programa de Residência pedagógica para a formação de futuros docentes de química, no qual nos proporcionam diversas experiências, como educador e pessoal. Na qual nos oportunizou diversos contatos fundamentais em uma escola, como o contato com os estudantes, professora de química, no qual foi possível o contato com professores de outras disciplinas.

Outro aspecto de suma importância, a formação de estudantes críticos reflexivos, de forma que a professora busca sempre despertar, no qual a falta de alguns recursos na escola não se torna um impe cílio para a realização de atividades experimentais. Dos muitos aspectos, outro bastante importante é a questão da relação da escola e família, no qual a escola busca sempre aproximar os pais das atividades, buscando deixar de lado essa barreira existente, sendo assim, que os estudantes estão sempre envolvidos em atividades promovidas fora da sala de aula, como café filosófico, teatro e até mesmo lançamento de livros.

Sendo possível a promoção de grandes experiências como futuro docente, mas, também sabemos que educação deve sempre ter uma melhoria, pois, um aspecto que chamou muita atenção em algumas salas, é a pontualidade e entrada e saída das aulas com grande frequência, sando que se tem uma grande influência no processo de ensino e aprendizagem dos mesmos, 
nos estudantes, com atividades de caráter investigativo, sempre buscando manter o contato com o cotidiano, questionando os estudantes sobre fenômenos químicos que ocorrem nos seus dia-dia de experimentos no ensino de química, pois não só está ligado a questão na compreensão dos conteúdos, mas também nas relações em sala de aula.

\section{Referências}

PIMENTA, Selma Garrido; LIMA, Maria do Socorro Lucena. Estágio e docência. 3. ed., São Paulo: Cortez, 2008.

ZEICHNER, Kenneth. M. A formação reflexiva de professores: idéias e práticas. Lisboa: Educa, 1993. p.12-52.

NÓVOA, Antonio (Org.). Profissão Professor. 2. ed. Porto: Porto, 1992.

GATTI, B. A. Formação de professores no Brasil: Características e Problemas. Educ. Soc. Campinas, v. 31, n. 113, p. 1355-1379, 2010.

HOLANDA, D. S; SILVA, C. S. M. A contribuição do Pibid na formação docente: Um relato de experiência. Anais do XI Encontro Nacional de Educação Matemática - ISSN 2178034X.p 1- 13, 2013.

SCHÖN, D. Formar professores como profissionais reflexivos. In: NÓVOA, A. Os professores e a sua formação. Lisboa: Dom Quixote, 1992. 158 p.

FREIRE, Paulo. Pedagogia da autonomia: saberes necessários à prática educativa. Rio de Janeiro: Paz e Terra, 1996.

PIMENTA, S. G; LIMA, M.S.L. Estágio e docência: diferentes concepções. ed. Revista Poíesis -Volume 3, Números 3 e 4, p.5-24, 2006.

GUIMARÃES, J. A. Regulamento do Programa Institucional de Bolsas de Iniciação a docência. Portaria nº 096, 2013. 